DR. ANDREAS STRASSER (Orcid ID : 0000-0002-8457-8242)

Received Date : 17-Jan-2017

Accepted Date : 20-Feb-2017

Article type : Invited Review

\title{
Cell Death and Thymic Tolerance
}

Stephen R. Daley ${ }^{1}$, Charis Teh ${ }^{2,3}$, Daniel Y. $\mathrm{Hu}^{4}$, Andreas Strasser ${ }^{2,3}$ and Daniel H.D. Gray $^{2,3}$

Affiliations: ${ }^{1}$ Infection and Immunity Program, Biomedicine Discovery Institute and Department of Biochemistry and Molecular Biology, Monash University, Melbourne. ${ }^{2}$ The Walter and Eliza Hall Institute of Medical Research. ${ }^{3}$ Department of Medical Biology, The University of Melbourne. ${ }^{4}$ IFREC, Osaka University, Japan.

Corresponding author:

dgray@wehi.edu.au

The Walter and Eliza Hall Institute

$1 \mathrm{G}$ Royal Parade

Parkville, VIC, 3052

+61393452497

Australia

This is the author manuscript accepted for publication and has undergone full peer review but has not been through the copyediting, typesetting, pagination and proofreading process, which may lead to differences between this version and the Version of Record. Please cite this article as doi:

$\underline{10.1111 / i m r .12532}$

This article is protected by copyright. All rights reserved 
Running title: Cell Death and Thymic Tolerance

\section{Summary}

The differentiation of haematopoietic precursors into the many functionally distinct $\mathrm{T}$ cell types produced by the thymus is a complex process. It proceeds through a series of stages orchestrated by a variety of thymic microenvironments that shape the $T$ cell developmental processes. Numerous cytokine and cell surface receptors direct thymocyte differentiation but the primary determinant of cell fate is the engagement of the T cell antigen receptor (TCR). The strength of the TCR signal and the maturation stage of the thymocyte receiving it can direct the various differentiation programs or, alternatively, end the process by inducing cell death. The regulation of thymocte death is critical for the efficiency of thymic $T$ cell differentiation and the preservation of immune tolerance. A detailed knowledge of mechanisms that eliminate thymocytes from the $T$ cell repertoire is essential to understand the "logic" of T cell selection in the thymus. This review focuses on the central role of the BCL-2 family of proteins in the apoptotic checkpoints that punctuate thymocyte differentiation and the consequences of defects in these processes.

Keywords: T Cells, Apoptosis/Autophagy, Cell Differentiation, Tolerance/Suppression/Anergy, Thymus

\section{Introduction}

Most thymocytes are destined to die via apoptosis. This feature is a consequence of the random nature of TCR gene recombination processes. TCR gene recombination allows for the massive breadth of receptors required to perceive the "universe" of pathogens; however, it also necessitates strict quality control mechanisms. Many nascent TCRs cannot interact with host MHC or MHC-like molecules and therefore cannot take part in immune responses and thus, are useless. Thymocytes expressing such TCRs and those 
lacking TCR expression (due to non-productive TCR gene rearrangement) are eliminated via a process termed "death-by-neglect". Other newly formed TCRs interact with host MHC:peptide complexes with such a high avidity that autoimmunity could ensue if the cells expressing them were to mature into $T$ cells that emigrate into the periphery. Thymocytes expressing such TCRs engage a range of programs that culminate in their cell death before they can complete $T$ cell differentiation. When, where and how thymocyte death occurs is the focus of this review. A detailed knowledge of mechanisms that eliminate thymocytes from the $T$ cell repertoire is essential to understand the "logic" of T cell selection in the thymus, which is a crucial component of both immunological self-tolerance and a functional immune system.

\section{Overview of thymic T cell differentiation}

The thymus is divided into two major anatomical zones: the outer cortex and the inner medulla. The early stages of thymocyte differentiation and TCR gene rearrangement occur in the cortex. This region is formed by a loose network of cortical thymic epithelial cells (cTEC) and blood vessels surrounded by dendritic cells, and is densely packed with immature thymocytes (1-3). As T cell differentiation proceeds, some thymocytes migrate to the medulla, which is composed of numerous medullary TEC (mTEC), dendritic cells, macrophages and B cells, all interacting with maturing thymocytes. The sequence of thymocyte differentiation can be resolved by expression of the TCR coreceptors, CD4 and CD8. The earliest thymocytes express neither co-receptor and are termed double negative (DN) cells, which compose approximately $2 \%$ of cells in the thymus. These give rise to double positive (DP) thymocytes that express both CD4 and CD8 and compose about $80-85 \%$ of thymic cells. DN and DP thymocytes predominantly occupy the cortical regions. Some DP thymocytes mature into either CD4 single positive (SP) or CD8 SP thymocytes that compose about $10-15 \%$ of thymic cellularity, and they reside in the medulla for 4-5 days prior to their export into the periphery (Figure 1) (4).

In the postnatal thymus, thymocyte differentiation commences with the periodic settlement of bone marrow-derived haematopoeitic precursor cells (5). These cells enter the thymus via large blood vessels at the junction between the cortex and medulla 
[reviewed in (1)]. The niche these precursors occupy provides delta-like 4 to ligate the Notch-1 receptor $(6,7)$, driving $T$ cell specification and initiating thymocyte differentiation [reviewed in (1)]. The normal mouse thymus can accommodate only $\sim 160$ T-cell progenitors, and only $\sim 10$ niches are open to colonisation by circulating progenitors at any moment in time (8). Progression of DN thymocytes through differentiation can be further delineated by expression of the cell surface proteins, CD44 and CD25: CD44 ${ }^{+}$CD25 (DN1) give rise to $\mathrm{CD}^{-} 4^{+} \mathrm{CD}^{-} 5^{+}$(DN2) which in turn become CD44-CD25 ${ }^{+}$ (DN3) and finally CD44CD25 (DN4) cells (9) (Figure 1). These stages involve migration through the cortex towards the outer capsule of the thymus [reviewed in (1)] and are punctuated by bursts of proliferation, differentiation and TCR gene rearrangement (10).

The rearrangement of the Tcrb, Tcrg and Tcrd loci (encoding the TCR $\beta$, TCR $\gamma$ and TCR $\delta$ chains, respectively) commences at the DN2 stage and is completed at DN3 (10). Thymocytes that produce functional $\mathrm{TCR} \gamma \delta$ receptors diverge at this stage of differentiation, maturing into $\mathrm{CD}^{-} \mathrm{CD}^{-} \gamma \delta \mathrm{T}$ cells that are exported to the periphery (10, 11). However, most thymocytes differentiate towards the $\alpha \beta T$ cell lineage and, for these cells, rearrangement of Tcrb is critical. Due to the random nature of this process, many of these rearrangements do not yield genes encoding functional proteins. Thymocytes incapable of producing a proper TCR $\beta$ chain cannot mature any further and die by apoptosis (12). The process initiated by expression of a functional TCR $\beta$ chain is referred to as beta selection. It involves pairing of the nascent TCR $\beta$ chain with an invariant pre-T $\alpha$ ( $\mathrm{pT} \alpha$ ) chain to form the pre-TCR which provides signals necessary for survival and progression to the DN4 and DP stages (12).

Beta selection involves $\sim 5$ rounds of proliferation, during which thymocytes downregulate CD25 to become DN4 cells and then swiftly upregulate CD4 and CD8 (13). Proliferation during beta selection accounts for $98 \%$ of all thymocyte proliferation (13), occurs in the outer cortex (14) and is required for the normal production of TCR $\alpha \beta$ lineage immature thymocytes and subsequently mature $\operatorname{TCR} \alpha \beta$ T cells (15). Tcra gene rearrangement commences in proliferating DP thymocytes $(16,17)$, which then cease dividing to become transcriptionally quiescent DP cells. DP thymocytes expressing 
nascent TCR $\alpha \beta$ heterodimers that are unable to bind MHC:peptide complexes die via apoptosis within about 3 days. Conversely, engagement of MHC:peptide complexes presented by CTEC provokes a transcriptional re-awakening (18), referred to as positive selection, that rescues the DP thymocyte from "death-by-neglect" and can induce further differentiation into the SP stage (Figure 1). The DP to SP transition also involves lineage determination, whereby cells expressing a TCR $\alpha \beta$ responsive to $\mathrm{MHC}$ I become CD8SP cells and those expressing a TCR $\alpha \beta$ responsive to MHC II become CD4SP (19). However, TCR ligation in DP thymocytes can also induce another fate in thymocytes: deletion by apoptotic cell death (Figure 1).

Soon after Miller's discovery that the thymus is required for a functional immune system (20), Burnet proposed that self-reactive lymphocytes are eliminated or inhibited in the thymus $(21,22)$ in mechanisms that came to be known as "negative selection" $(23)$. The current nomenclature is more specific, with elimination of self-reactive thymocytes being described as "deletion", while differentiation of self-reactive thymocytes into a range of alternative $T$ cell types, including lineages with known or putative regulatory functions, is described as "agonist selection" (24). The idea that thymic deletion of highly self-reactive cells is an essential immune tolerance mechanism has held sway for decades. However, while millions of cells are deleted in the thymus every day during the generation of multiple T cell lineages that are necessary for safe, effective immunity (reviewed below), the importance of thymic deletion for preventing autoimmune disease is still not completely clear.

\section{Apoptotic checkpoints in thymocyte differentiation}

Genetic control of thymocyte death

Numerous cell death mechanisms shape immune cell differentiation and function, including caspase-dependent apoptosis via the intrinsic (also called mitochondrial or BCL-2 regulated) pathway, the death receptor (also called extrinsic) pathway (25-27), and caspase-independent necroptosis via activation of RIPK1, RIPK3 and MLKL (28). Thymocyte differentiation appears overtly normal in mice rendered deficient in both the death receptor and necroptotic cell death pathways $(29,30)$, indicating that these 
pathways are not essential for thymocyte death under steady-state conditions. However, mice with partial or complete defects in the intrinsic pathway of apoptosis display gross abnormalities in thymocyte differentiation, including impaired death-by-neglect and TCR $\alpha \beta$-induced deletion (31-35).

The intrinsic pathway of apoptosis is regulated by members of the BCL-2 family of proteins. Members of this family share homology with the founding member, BCL-2, and can be divided into three main factions: 1) the apoptosis-initiating BH3-only proteins, 2) the pro-survival proteins and, 3) the pro-apoptotic effector proteins, BAX and BAK (and perhaps the little studied $\mathrm{BOK})(36,37)$. The $\mathrm{BH} 3-$ only proteins are the critical initiators of the apoptotic cascade and this group includes BIM, PUMA, NOXA, BAD, BIK, HRK, $B M F$ and $\operatorname{BID}(35,36,38)$. In healthy cells, the pro-survival proteins BCL-2, BCL- $X_{L}$, MCL-1, BCL-W and BFL-1/A1 antagonize the BH3-only proteins to inhibit BAX and BAK activation (36). Thus, a simple model holds that the balance between the pro-death $\mathrm{BH} 3-0 n l y$ proteins and the pro-survival proteins determines whether BAX and BAK become activated at the mitochondria. Furthermore, certain $\mathrm{BH}$-only proteins have been shown to be able to also activate BAX/BAK directly (39). Yet, a recent study has shown that apoptosis can occur without the need for direct activation of BAX/BAK by any BH3-only protein (40), emphasizing the importance of restraint of BAX/BAK activation by the pro-survival BCL-2 family members. Regardless of the precise modes of activation, different cytotoxic stimuli engage various transcriptional and post-transcriptional mechanisms that cause the BH3-only proteins to overwhelm the pro-survival BCL-2-like proteins and induce the activation of the BAX/BAK effector proteins. The activation of $B A X$ and BAK involves conformational changes that lead to disruption of the mitochondrial outer membrane (MOMP), allowing the release of apoptogenic factors such as cytochrome c or SMAC/DIABLO (36). Cytochrome C interacts with cytosolic APAF-1 to form the "apoptosome", a large complex with seven-fold symmetry that activates pro-caspase-9 (41-43). SMAC (second mitochondrial-derived activator of caspases, also known as DIABLO) promotes apoptosis by blocking the X-linked inhibitor of apoptosis protein (XIAP) that normally inhibits the activation of certain caspases (4446). These interactions lead to activation of the so-called effector caspases-3, -6 and -7 
that proteolytically cleave hundreds of vital cellular proteins (43) and prevent the release of "danger signals" $(47,48)$ to mediate apoptosis.

BAX and BAK have largely overlapping functions and only the loss of both completely blocks the intrinsic pathway of apoptosis. The blockade of this pathway causes developmental defects that lead to early post-natal lethality in almost all mice (49). In haematopoietic chimeras created using $\mathrm{Bax}^{-/} \mathrm{Bak}^{-/}$stem/progenitor cells, thymocyte death in response to a range of stimuli (including TCR $\alpha \beta$ ligation) was completely inhibited and there were marked increases in DN, CD4SP and CD8SP thymocytes and concomitant reduction in DP cells (34). Similar findings were observed earlier in mice over-expressing the pro-survival protein, BCL-2, that inhibits the intrinsic pathway of apoptosis (31) and in mice lacking the BH3-only protein BIM (33). The reduction of DP cells was a progressive phenotype (34) that might be attributed to: 1) negative feedback from the mature thymocytes that accumulated, 2) alteration of the thymic microenvironment, and/or 3) reduced proliferation in the DN precursor compartment. These and other findings demonstrated that thymocyte death associated with the deathby-neglect and deletion checkpoints depend on the BH3-only protein BIM for initiation and BAX/BAK for execution of the intrinsic pathway of apoptosis.

How this cell death pathway is activated throughout thymocyte differentiation varies. The expression profiles of the various BCL-2 family members differ among cell types and different cytotoxic stimuli exert distinct changes in the profiles of $\mathrm{BH} 3-$ only and prosurvival proteins. The upstream mechanisms that trigger the intrinsic pathway of apoptosis in thymocytes depend upon the stage of development, location of the cells and nature of the stimulus.

\section{Failure of TCR beta selection}

The first major wave of apoptosis during thymocyte differentiation accompanies the completion of Tcrb rearrangement at DN3 (50). Thymocytes that do not recombine a functional Tcrb gene (or Tcrg and Tcrd) are unable to express the pre-TCR, formed by the new TCR $\beta$ chain and $\mathrm{pT} \alpha$. Pre-TCR signaling is required to induce transcriptional 
changes required for proliferation, cessation of Tcrb rearrangement and further differentiation and survival. These signals rely, at least in part, upon elements of the TCR signaling machinery and culminate in calcium flux, NFKB activation and cessation of FoxO3 activity $(12,51-53)$. The precise mechanism that induces the apoptosis of thymocytes failing beta selection remains unclear. Data implicate both the intrinsic and death receptor pathways of apoptosis in this process.

One study reported that a level of the DNA damage associated with Tcrb recombination was attended by increased levels of the tumor suppressor protein, p53 which, in turn, upregulated BID (51). However, most evidence indicates that p53 activity induces PUMA and NOXA, but not BID. Also, BID-deficient mice engage normal DNA-damage induced apoptosis and have normal thymocyte differentiation (54). Another pathway reported to enforce the beta selection pathway involved the activity of the transcription factor, FoxO3, inducing the expression of BIM to cause apoptosis of thymocytes lacking preTCR signaling (51). Yet, mice in which Foxo-mediated regulation of Bim transcription was abolished had no evidence of a beta selection defect (55), indicating that this mechanism is not a primary mediator of this apoptotic checkpoint in the thymus.

Nevertheless, there is evidence that upregulation of pro-survival BCL-2 proteins is an important element of beta selection. Engagement of pre-TCR signaling induces NFKB activation and upregulation of the pro-survival BCL-2 family member, A1 (or BFL-1 in humans) $(50,56)$, presumably to antagonize pro-apoptotic BH3-only proteins, such as $\mathrm{BIM}$, and the effectors BAX/BAK. This survival mechanism ensures that only progenitors that productively rearrange the TCR $\beta$ chain progress to the DP stage of differentiation (Figure 1). Evidence from haematopoietic chimeras with BAX- and BAK-deficient thymocytes suggests that blocking the intrinsic pathway of apoptosis causes defective beta selection and impedes the efficiency of early thymocyte differentiation (34). However, BCL-2 overexpression did not rescue cells failing the beta selection checkpoint in SCID mice (57), which are unable to rearrange TCR genes due to a mutation in Prkdc $(58,59)$. Therefore, the precise role of the intrinsic pathway of apoptosis in beta selection remains an open question that warrants further investigation. 
Relevant to this question, Newton et al., found that a dominant negative FADD transgene, which inhibits the death receptor pathway of apoptosis, could bypass the beta selection blockade induced by RAG-deficiency (60). This study raises the intriguing possibility that coordination of death receptor and TCR signals are the critical determinants of thymocyte beta selection.

\section{Death-by-neglect}

The DP stage of thymocyte differentiation is unusual. The transition from the DN to the DP stage is accompanied by the largest change in transcriptome throughout $T$ cell differentiation, characterised by the downregulation of almost 1,500 genes and relative metabolic quiescence (18). Most DP thymocytes survive for about 3 days (61) during which time they "audition" for the process of positive selection. DP thymocytes have the capacity to undergo multiple rearrangements of the Tcra genes during their lifespan to maximize their chances of producing a TCR $\alpha \beta$ that can be positively selected (62). These cells must produce a TCR $\alpha \beta$ capable of interacting with MHC:self-peptide complexes by rearranging their Tcra locus; otherwise they undergo death-by-neglect. BCL-2 overexpression can promote the survival of thymocytes bearing TCR $\alpha \beta$ that cannot interact with the host MHC $(57,63)$, indicating that death-by-neglect is mediated by the intrinsic apoptotic pathway.

Although it remains unclear which BH3-only protein(s) are responsible for inducing death-by-neglect, BCL- $X_{L}$ appears to be the key pro-survival protein (Figure 1). BCL- $X_{L}$ is markedly upregulated during the DN to DP transition and $B C L-X_{L}$-deficiency causes excessive apoptosis of DP, but not SP thymocytes (64). The nuclear orphan receptor, $\mathrm{ROR} \gamma$ and its thymus-specific relative, ROR $\gamma$ t, may contribute to the control of BCL- $X_{L}$ levels in DP thymocytes, because mice lacking these transcription factors exhibit loss of $B C L-X_{L}$ expression and a reduction in DP lifespan $(65,66)$. Over-expression of BCL- $X_{L}$ (or BCL-2) can extend the lifespan of wildtype DP thymocytes and rescues their loss in $R O R \gamma^{-1-}$ mice $(65,67)$. One consequence of an extended DP thymocyte lifespan is the increased usage of TCR $\alpha$ chains that incorporate more 3' J alpha gene segments (i.e. 
more distal) (67), indicating that death-by-neglect influences the TCR repertoire that can be positively selected.

An interesting feature of this primary role for $B C L-X_{L}$ in $D P$ thymocyte survival is a parallel with the molecular control of platelet survival. A "molecular timer" function for $B C L-X_{L}$ has been proposed in platelets, whereby the degradation of $B C L-X_{L}$, (with a 20 $\mathrm{h}$ half-life, shorter than that of BAX/BAK but much longer than the 20 min half-life of MCL-1, on which many metabolically active cell types rely (36)) eventually allows BAK (and to a lesser extent BAX) activation and apoptosis, thereby limiting the lifespan of this metabolically inactive blood cell type (68).

TCR $\alpha \beta$ signals received during positive selection switch the pro-survival profile of thymocytes from a reliance on BCL- $X_{L}$ to BCL-2 and MCL-1 (69-71). This switch offsets the increased BIM levels that are also a consequence of TCR $\alpha \beta$ ligation, supporting the differentiation of SP thymocytes (Figure 1). However, positive selection involves more than basic survival signals, because BCL-2 overexpression or BIM-deficiency are not sufficient to promote the further differentiation of DP thymocytes that do not receive a TCR $\alpha \beta$ signal $(32,33,57,63,72)$.

Should the TCR $\alpha \beta$ signal received by thymocytes exceed a certain threshold, the balance tips towards a pro-apoptotic signal. This TCR $\alpha \beta$ driven form of apoptosis is referred to as deletion and is one of the major mechanisms of negative selection. The remainder of this review will focus on the current understanding of the mechanisms of deletion and how they influence immune tolerance.

\section{The "when" and "where" of thymocyte deletion}

Identification of the sites and stages of thymocyte deletion has been a major focus in the field, because an understanding of these parameters reveals the "logic" of how deletion sculpts the $T$ cell repertoire. Resolution of these issues has been surprisingly controversial, in part due to the variety of experimental approaches employed. We summarise the main approaches and current hypotheses in this section. 


\section{Evidence for deletion based on the absence of antigen-reactive thymocytes or $T$ cells}

Early evidence consistent with deletion was based on the absence of expected immune responses. Medawar's transplantation of allogeneic tissues and cells into fetuses (73) and subsequent transplantation studies [reviewed in (74)] showed that tolerance to alloantigens could be acquired, but whether the allo-reactive lymphocytes were deleted or inhibited was unclear. Direct evidence of deletion came with the advent of flow cytometry and monoclonal antibodies, when mouse strains that expressed the MHC Class II molecule, I-E, were shown to have a profound reduction in mature thymocytes bearing TCRs that are activated by complexes of I-E with certain so-called superantigens (75, 76). Studies of $\mathrm{TCR} \alpha \beta$ transgenic mice confirmed that thymocyte deletion could be mediated by TCR $\alpha \beta$ ligation by MHC/peptide complexes (77) and that deletion could occur either at the DP stage or during the DP to SP transition (78). Using a TCR transgene to reduce $T C R \alpha \beta$ diversity to the endogenous TCR $\alpha$ chains, and a peptide/MHCII tetramer to detect an enlarged population of moth cytochrome c (MCC)reactive T cells, deletion mediated by MCC expression was found to be already $60 \%$ complete in large thymocytes, presumably proliferating during beta selection, and became progressively more complete as thymocyte development advanced (79). In a recent study using tetramers to quantify peptide/MHCII-reactive TCR $\alpha \beta \mathrm{T}$ cells in the entire mouse, the extent of deletion was found to correlate with the number of thymic antigen presenting cells expressing the peptide-containing self-antigen (80). The wide variation in the extent and maturation stage at which deletion can occur underlines the need to define the sites and stages at which deletion occurs in the natural TCR $\alpha \beta$ repertoire.

\section{Evidence for deletion based on the distribution of apoptotic cells}

Apoptotic cells may be detected in situ via terminal deoxynucleotidyl transferase dUTP nick end labeling (TUNEL). In TCR V $\beta 5$-transgenic mice (in which the TCR V $\beta 5$ on thymocytes is stimulated by an endogenously expressed superantigen), large numbers of apoptotic TUNEL ${ }^{+}$cells were observed within the thymic medulla (81). TUNEL ${ }^{+}$cells could also be observed within the cortex of wild-type mice, but this was not obviously 
different in mice with or without MHC Class I and II expression (81). The authors concluded that deletion occurs within the thymic medulla and death-by-neglect occurs in the thymic cortex. However, as there was no quantitative analysis of $\mathrm{TUNEL}^{+}$cells, the data do not exclude the possibility that deletion can also occur in the thymic cortex. Indeed, in other TCR $\alpha \beta$ transgenic models of thymocyte deletion, cortical TUNEL staining correlated with deletion at the DP stage and medullary TUNEL staining correlated with deletion at the SP stage (82). Thymocytes committed to apoptosis can also be detected by their expression of active caspase-3, a late event in the apoptotic cascade. In the $\mathrm{H}-\mathrm{Y}^{\mathrm{CD} 4} \mathrm{TCR} \alpha \beta$ transgenic model of deletion, active caspase $-3^{+}$ thymocytes were observed adjacent to dendritic cells within the thymic cortex (83). In mice with a natural TCR $\alpha \beta$ repertoire, $~ 25 \%$ of active caspase $3+$ thymocytes have a CD5+ CD69+ phenotype (84). The CD5+ CD69+ subset of active caspase 3+ thymocytes is absent in mice lacking MHC Class I and II or TCR $\alpha \beta$ expression, indicating that the formation of this population requires MHC-dependent TCR $\alpha \beta$ signalling (85). These findings suggest that deletion can occur in either the thymic cortex or medulla, and may account for $\sim 25 \%$ of all thymocyte apoptosis in the adult mouse thymus.

\section{Evidence for deletion based on real-time imaging}

Two-photon microscopy has been used to image thymocytes in positive and negative selecting conditions in thymic slices. DP thymocytes are able to burrow into thymic slices, whereupon they reside and migrate exclusively in the cortex (86). CXCR4 is required to retain thymocytes in the thymic cortex, whereas interactions between CCR7 and CCL19/21 are required for the normal retention of human and mouse thymocytes in the thymic medulla $(86,87)$. DC were observed within the cortex adjacent to blood vessels, and in the vicinity of the CCR7 ligand, CCL21 (3). The authors proposed that thymocytes that receive a TCR $\alpha \beta$ signal from CTECs upregulate CCR7 and migrate towards CCL19/21-associated cortical DC, which control "TCR repertoire selection" in that location. Consistent with this notion, when thymic slices were perfused with ovalbumin (OVA) peptide, OVA-specific OT-I TCR $\alpha \beta$ transgenic thymocytes in the thymic cortex preferentially interacted with DC, accumulated high levels of intracellular calcium and 
nuclear translocated NFAT (88). In the thymic cortex, the average interaction time between OT-I thymocytes and $\mathrm{OVA}^{+} \mathrm{DC}$ was $\sim 1$ hour, whereas signalling events in positive selecting conditions (characterised by lower-amplitude increases in intracellular calcium) averaged 4 minutes (88). The F5 TCR $\alpha \beta$ binds to a peptide derived from influenza virus (NP) presented by MHC class $I D^{b}$. In the thymic cortex, F5 DP thymocytes arrested their migration within minutes of NP peptide addition, and migratory arrest persisted for several hours (89). These results indicate that thymocytes can perceive a strong $\mathrm{TCR} \alpha \beta$ signal within the thymic cortex.

Real-time imaging of medullary thymocytes in negative selecting conditions has produced interesting, albeit variable results. As observed in the cortex, medullary F5 TCR $\alpha \beta$ thymocytes arrested their migration and increased their intracellular calcium concentration within minutes of NP peptide addition to thymic slices (89). In contrast, OT-I TCR $\alpha \beta$ thymocytes encountering endogenous OVA under the control of rat insulin promoter (RIP-mOVA) migrated 33\% slower than under positive selecting conditions and exhibited a "confined" migration pattern, interacting repetitively with DC within $30 \mu \mathrm{m}$ of their original position (90). In another study, OVA-specific OT-II TCR $\alpha \beta$ transgenic CD4SP cells clustered around Aire ${ }^{+}$ICAM-1 ${ }^{\text {hi }}$ foci in the thymic medulla at 1 and $5 \mathrm{~h}$ after being added to RIP-mOVA thymic slices, whereas OT-II TCR $\alpha \beta$ CD4SP cells observed at $24 \mathrm{~h}$ were not clustered and were highly motile (91). The study that found confined migration analysed thymocytes that had developed within the thymic tissue being analysed (90), whereas the studies that found migratory arrest and clustering in the thymic medulla analysed thymocytes that had been added to the thymic slices by the investigators $(89,91)$. To reconcile these observations, it is possible that self-reactive thymocytes in the medulla may regain motility if they survive an initial period of migratory arrest due to strong $T C R \alpha \beta$ signalling.

\section{Quantification of deletion}

Two studies used apoptosis-defective mice to "capture" and quantify TCR $\alpha \beta$-signaled thymocytes that would normally be deleted. Using Nur77-GFP mice, in which thymocytes upregulate GFP in proportion to TCR signal strength (92), it was estimated 
that $57 \%$ of TCR-signalled DP thymocytes are deleted (84). Using CD69 expression to identify TCR $\alpha \beta$-stimulated cells within nascent thymocyte cohorts labelled with the thymidine analogue, BrdU, we estimated that $55 \%$ of TCR $\alpha \beta$-stimulated thymocytes are deleted at the CCR7- stage, which is analogous to the DP stage (93). Another study, which focused on the dynamics of thymocyte progression or death throughout development, concluded that $67 \%$ of TCR $\alpha \beta$-stimulated DP thymocytes are deleted (94). Estimates of the extent of deletion later in thymocyte development were more variable, ranging from $20-63 \%$ within the CD4SP stage, and $42-55 \%$ within the CD8SP stage (84, $93,94)$. The consensus from this trio of studies is that more than half of all TCR $\alpha \beta-$ stimulated thymocytes are deleted at the DP stage of development, before the thymocytes upregulate CCR7, and that fewer thymocytes are deleted at the subsequent SP stages.

A recent study enumerated human $\mathrm{T}$ cells capable of binding $\mathrm{MHC}$ I tetramers loaded with a self-peptide derived from the SMCY/H-Y antigen, which is encoded on the $Y$ chromosome (95). Compared to women, in whom the SMCY/H-Y antigen would be foreign, men were found to have approximately one-third of the number of $T$ cells capable of binding this male-specific self-antigen. The authors concluded that deletion prunes (by $\sim 66 \%$ ) but does not eliminate self-reactive CD8 T cells. A comparison of men and women is appropriate if one wishes to measure deletion mediated specifically by $Y$ chromosome-encoded self-antigens, but this comparison neglects deletion mediated by self-antigens encoded on other chromosomes, which are present in both men and women. Mice lacking B cells had only a 7-fold increase in T cells capable of binding $\mathrm{MHCll}$ tetramers loaded with a self-peptide expressed only by B cells (96). However, mice in which deletion is truly defective, because MHCll expression was confined to cortical thymic epithelial cells, had 450 -fold more $T$ cells capable of binding the same tetramer (96). Out of a panel of $19 \mathrm{TCR} \alpha \beta$ receptors ascertained to drive deletion in C57BL/6 mice, approximately one-third were responsive to both $\mathrm{MHCl}$ and $\mathrm{MHCII}$ (97). Notably, of the 12 deletion-inducing TCR $\alpha \beta$ receptors that were tested in vivo, cells expressing 11 of them were found to be deleted at the CCR7- stage and one drove deletion at the CCR7+ stage (97). The deletion of most T cells capable of binding to an 
individual self-antigen need not be mediated by that self-antigen. Rather, many selfreactive TCR $\alpha \beta$ receptors bind to more than one self-antigen, any of which may mediate deletion, which predominately occurs before the thymocytes upregulate CCR7.

\section{"How" does thymocyte deletion occur?}

The cell death pathway that provokes thymocyte deletion is the intrinsic pathway of apoptosis with no contribution from the death receptor pathway (98). BCL-2 overexpression, as well as elimination of BAX and BAK, inhibits thymocyte deletion mediated via TCR stimulation by superantigens $(31,34)$ and conventional antigens $(63)$. BIM is required for normal formation of active caspase-3+ thymocytes in deleting conditions (99) and for anti-CD3 antibody-mediated thymocyte apoptosis (32, 33, 100). In non-transgenic mice with a normal $\mathrm{TCR} \alpha \beta$ repertoire and in $\mathrm{TCR} \alpha \beta$ transgenic models of thymocyte deletion, mice lacking both BIM and PUMA have more maturephenotype CD24 ${ }^{\text {low }}$ CD4SP TCR $\alpha \beta$ cells than mice lacking BIM alone, which indicates that PUMA cooperates with BIM in T cell deletion (72). BIM acts in a dose-dependent fashion: thymocytes from $\mathrm{Bim}^{+/}$heterozygous mice have an intermediate defect in deletion of autoreactive thymocytes (32), suggesting that BIM induction represents a key point in the pathway where $\operatorname{TCR} \alpha \beta$ signal strength is translated into opposite outcomes of survival or apoptosis.

An important feature of these studies is that the self-reactive thymocytes "rescued" from deletion by BIM-deficiency may be found in different peripheral $\mathrm{T}$ cell lineages and organs depending on the maturation stage at which they received a strong TCR $\alpha \beta$ signal. BIM-deficient thymocytes rescued from deletion initiated at the DP stage attain a CD4- CD8 $\alpha$ - phenotype in the thymus and spleen (99) and/or differentiate into CD4CD8 $\beta-$ CD8 $\alpha \alpha^{+}$small intestinal intraepithelial lymphocytes (CD8 $\alpha \alpha^{+}$SI-IEL) (101). BIMdeficient thymocytes rescued from deletion at the CD8SP stage can become CD8+ T cells in the spleen, but upon stimulation these cells have impaired proliferation and cytokine production compared to naïve CD8+ T cells (102). Peripheral self-reactive SMCY/H-Y-specific TCR $\alpha \beta C D 8+T$ cells in humans also show these functional impairments (95). Mice lacking BIM have expanded populations of $C D 73^{\text {high }} \mathrm{FR} 4^{\text {high }}$ 
CD44 high "anergic" CD4+ TCR $\alpha \beta$ T cells (84) and Foxp3+ T-reg cells (especially the CD25- subset) $(103,104)$. These expanded populations might contain the progeny of BIM-deficient thymocytes rescued from deletion at the CD4SP stage.

Thymocyte deletion involves the induction of the orphan steroid receptor, Nur77 $(92,105$, 106). Transgenic expression of wild-type Nur77 induces thymocyte apoptosis whereas a dominant-negative Nur77 protein inhibited peptide-mediated deletion of TCR $\alpha \beta$ transgenic thymocytes, but not superantigen-mediated deletion (107). Nur77-deficiency had no effect in other $T C R \alpha \beta$ transgenic models, such as $H Y^{C D 4}$ thymocytes in either positive or negative selecting conditions (108) but it did increase the numbers of OT-II CD4SP TCR $\alpha \beta$ thymocytes in both positive and negative selecting conditions (109). Nur77's function in thymocyte selection remains unclear but may extend beyond the proapoptotic role initially hypothesised (110), as Nur77-deficient thymocytes were found to have reduced mRNAs encoding enzymes required for energy utilization (109).

\section{Relationship of thymocyte deletion to agonist selection}

Like deletion, agonist selection is initiated by strong TCR $\alpha \beta$ signaling and occurs at multiple stages of thymocyte development. Defects in apoptosis increase the number of $\mathrm{T}$ cells that complete agonist selection, suggesting that apoptotic deletion eliminates many thymocytes unfit to enter the $T$ cell lineages induced by agonist selection. However, little is known about the factors that determine whether a strongly TCR $\alpha \beta$ signalled thymocyte undergoes deletion or agonist selection. As the thymocyte response

to strong TCR $\alpha \beta$ signaling varies with maturation stage, factors that determine the fate of self-reactive thymocytes may be stage-specific.

\section{Early agonist selection: intestinal intraepithelial CD8 $\alpha \alpha+T$ cell differentiation}

In some $T C R \alpha \beta$ transgenic mouse strains, in addition to inducing deletion, high-affinity self-antigen expression in the thymus drives differentiation of CD8 $\alpha \alpha+$ SI-IEL (111). While most thymocytes forced to express TCR $\alpha \beta$ receptors derived from CD8 $\alpha \alpha^{+}$SI-IEL are deleted, some differentiate into CD8 $\alpha \alpha^{+}$SI-IEL after passing through a CD4 ${ }^{-} \mathrm{CD}^{-}$ 
stage in the thymus $(101,112)$. Downregulation of CD4 and CD8 expression in thymocytes, so that the cells attain a DN (also called "DPdull,") phenotype, is a hallmark of the response to strong $T C R \alpha \beta$ signaling in DP thymocytes $(83,93,113)$. Within the DN population, markers that distinguish post-selection strongly $\mathrm{TCR} \alpha \beta$-signalled thymocytes from pre-selection thymocytes include TCR $\beta$, PD-1 and the IL-2 receptor $\beta$ chain, CD122 $(83,114,115)$. Mice with defective TCR $\alpha \beta$ stimulation-induced apoptosis, such as BIM-deficient animals, have a marked increase in TCR $\beta+$ DN thymocytes $(32,33$, 116) and CD8 $\alpha \alpha^{+}$SI-IEL (101), indicating that apoptotic deletion normally limits the number of thymocytes that complete this pathway of early agonist selection.

CD8 $\alpha \alpha^{+}$SI-IEL are absent in $\beta 2$-microglobulin-deficient mice (117). Among DP thymocytes, $6-9 \%$ of cells bind to tetramers of thymic leukaemia (TL) antigen (114), a $\beta 2$-microglobulin-dependent $\mathrm{MHC}$ class I-like molecule that binds to CD8 $\alpha \alpha$ homodimers (118) and is highly expressed by intestinal epithelial cells (119). DP thymocytes that bind to TL (called CD8 $\alpha \alpha+$ DP hereafter) exhibit a greater capacity for CD8 $\alpha \alpha^{+}$SI-IEL differentiation than other DP thymocytes (114). $\beta 2$-microglobulindeficient mice have some CD8 $\alpha \alpha+$ DP cells but lack the TCR $\beta+$ subset (114), indicating that CD8 $\alpha \alpha$ expression precedes, and TCR $\beta$ expression is induced by, a TCR $\alpha \beta$ signal in DP thymocytes. Unlike CD8 $\alpha \alpha+$ DP thymocytes, which require intra-thymic injection, agonist-selected TCR $\beta^{+}$DN thymocytes are able to become CD8 $\alpha \alpha^{+}$SI-IEL after injection into the blood stream (114). The absolute number of TCR $\beta^{+} \mathrm{DN}$ thymocytes increases in the absence of CD28 or its ligands, CD80 and CD86 (116). This finding indicates that co-stimulation promotes deletion in DP thymocytes that receive a strong TCR $\alpha \beta$ signal. Thus, two factors that affect the probability of undergoing deletion or early agonist selection into the CD8 $\alpha \alpha^{+}$SI-IEL lineage are, first, whether pre-selection DP thymocytes express CD8 $\alpha \alpha$ homodimers and second, variation in CD28 costimulation.

\section{Late agonist selection: T-reg differentiation}


FOXP3 is a transcription factor required for the suppressive function of T-reg cells (120, 121), which are continuously required to prevent inappropriate T-cell activation (122). In humans, IPEX (immunodysregulation, polyendocrinopathy and enteropathy, X-linked syndrome) is caused by mutations in $\operatorname{FOXP3}(123,124)$. FOXP3+ cells are markedly increased in the thymus and periphery of mice with defective TCR $\alpha \beta$ stimulation-induced apoptosis $(103,104)$, such as BIM-deficient animals, indicating that apoptotic deletion normally limits T-reg differentiation. As FOXP3+ T-reg cell differentiation has been reviewed recently (125), here we concentrate on how apoptotic deletion impinges on Treg differentiation in the thymus.

Although T-reg differentiation has FOXP3-independent components $(120,126)$, FOXP3 upregulation is a key event in the experimental analysis of thymic T-reg differentiation. Foxp3 upregulation occurs mainly in mature CD4SP cells that already express CCR7 $(85,127)$. Since the majority of thymocyte deletion occurs before CCR7 upregulation, a primary outcome of deletion is to eliminate self-reactive thymocytes before they mature sufficiently to upregulate FOXP3.

The thymic medulla contains a "mosaic" of tissue-restricted self-antigens with focal expression patterns (128), providing thymocytes that received a weak TCR $\alpha \beta$ signal at the cortical CCR7- stage an opportunity to receive a strong TCR $\alpha \beta$ signal at the subsequent medullary CCR7+ stage. Unlike CCR7- DP or CD4SP thymocytes, the response of CD4SP CCR7+ thymocytes to strong $\mathrm{TCR} \alpha \beta$ signalling overlaps substantially with the response of activated mature $T$ cells, including induction of genes that require CARD11 signalling to activate NF-кB (93). At the CD4SP CCR7+ stage the outcome of the first strong TCR signaling event is determined by competition between a BIM-dependent pro-deletion program and a CARD11/NFKB-dependent pro-survival program. Normally, the latter program is successful in only a minority of cells (93). This pro-survival function of CARD11 at the CD4SP CCR7+ stage contrasts with its function in DP thymocytes, in which CARD11 is required for deletion (93). The mechanisms underlying CARD11's stage-specific functions in thymocyte deletion are enigmatic, but 
parallel the functions of CD28, which is also required for deletion at the DP stage (116) and T-reg differentiation at the CD4SP stage (129-131).

Thymic T-reg differentiation has been characterised as a two-step process consisting of strong TCR $\alpha \beta$ signalling followed by cytokine-induced FOXP3 upregulation (132). Thymic FOXP3+ cells are almost completely absent in mice lacking any of the three subunits of the IL-2 receptor (133). Cytokine signaling has been postulated to prevent deletion induced by strong TCR $\alpha \beta$ signalling (134). An alternative hypothesis is that cytokine receptor signalling counteracts a pro-apoptotic protein signature, which is induced in developing T-reg cells by FOXP3 itself (104). Distinguishing between these possibilities is important to advance our understanding of both deletion and T-reg differentiation in self-reactive CD4SP CCR7+ thymocytes.

There are two schools of thought regarding the cell fate "decision" in self-reactive CD4SP CCR7+ thymocytes poised to undergo deletion or T-reg differentiation. The "avidity hypothesis" holds that strong and intermediate TCR $\alpha \beta$ signaling induce deletion and T-reg differentiation, respectively $(128,135)$. Consistent with this view, among CD4SP thymocytes from Nur77-GFP reporter mice, the FOXP3+ population has intermediate GFP expression above the FOXP3- CD25- subset and below the FOXP3CD25+ subset $(92,136)$. However, CD4SP cells rescued from deletion in BIM-deficient Nur77-GFP mice have similar GFP expression to the FOXP3+ population (84). A second finding in support of the "avidity hypothesis" is that decreasing the level of MHCII expression in mature mTECs simultaneously impaired deletion and increased T-reg differentiation mediated by mTEC-presented self-antigens (135). In this study, the proportion of T-reg cells in the self-reactive CD4SP population was similar in the presence of normal or reduced MHCII expression (135), which contrasts with marked increases in the proportion of T-reg cells observed when the frequency of CD4SP cells expressing the same self-reactive $T C R \alpha \beta$ was reduced to low (more physiological) levels, reducing intraclonal competition $(137,138)$. A stern test of the "avidity hypothesis" would be to investigate whether reducing MHCIl expression in mature mTECs still enhances T-reg differentiation under conditions of low intraclonal competition. One 
weakness of the "avidity hypothesis" is that it conflicts with evidence that T-reg differentiation can require stronger $\mathrm{TCR} \alpha \beta$ activation than deletion (139).

Drawing on findings from a range of approaches described above, we wish to propose an alternative view, which we term the "collaboration hypothesis". After surviving the first strong TCR $\alpha \beta$ signalling event in the thymic medulla in a CARD11/NFKB-dependent manner, self-reactive thymocytes begin to migrate within a confinement zone, which is circumscribed by DCs and contains a high-affinity self-antigen, forming just one piece of a broad "mosaic" of self-antigens $(90,91,128)$. Thymic DC represent a source of IL-2 that is important for normal T-reg differentiation (140). During a period of "collaboration" that lasts 1-2 days (85), self-reactive TCR $\alpha \beta$ CD4SP CCR7+ thymocytes might induce local DC to produce IL-2. Self-reactive TCR $\alpha \beta$ CD4SP CCR7+ thymocytes that fail to "collaborate" efficiently with DC may be starved of IL-2 and undergo growth factor withdrawal induced apoptosis. If IL-2 production scales with the avidity of "collaborations", it would explain why TCR $\alpha \beta$ receptors with higher avidity for selfantigen facilitate the development of larger thymic T-reg cell populations $(141,142)$. IL-2 protein was found to have a focal distribution in the thymic medulla (143). Opposite to the "avidity hypothesis", the "collaboration hypothesis" posits that deletion prevents TCR $\alpha \beta$ CD4SP CCR7+ thymocytes with too low avidity for self-antigen from becoming T-reg cells. This would explain the finding that T-reg associated TCR $\alpha \beta$ receptors have an extremely high avidity for self-antigen (142), exceeding the threshold required for apoptotic deletion $(139,144)$.

\section{Perspectives}

Thymocytes unfit for selection into any $T$ cell lineage are eliminated at four checkpoints in the thymus. Two of these checkpoints, beta selection and death by neglect, eliminate thymocytes that fail to express a TCR $\alpha \beta$ capable of engaging any self-MHC ligand, precluding their participation in immune responses. The other two checkpoints delete thymocytes bearing an $\mathrm{TCR} \alpha \beta$ that binds strongly to a self-MHC ligand either early or late in thymic development. 
In the literature the latter two checkpoints are commonly conflated into one entity termed deletion, or negative selection. This fusion is understandable because it remains unclear whether the delineation between the two checkpoints is sharp or blurred. In other words, it is unclear whether the self-antigens, TCR $\alpha \beta$ repertoires and molecular mediators involved at the two checkpoints are discrete or overlapping. These are directions for future research. However, the two deletion checkpoints, which we term "wave 1 deletion" and "wave 2 deletion" (Figure 1), are distinguished by (i) the divergent phenotypes that the self-reactive thymocytes attain, (ii) the different times required to reach them after thymocytes proliferate during beta selection and (iii) the different $T$ cell lineages that arise from the rare cells which survive strong $\mathrm{TCR} \alpha \beta$ activation and undergo agonist selection.

Wave 1 is the larger deletion checkpoint and likely occurs in the thymic cortex. It is unclear whether the probability of deletion versus CD8 $\alpha \alpha+$ SI-IEL differentiation at this early checkpoint is influenced by $T C R \alpha \beta$ specificity. If so, is the outcome influenced by whether the TCR $\alpha \beta$ is activated by $\mathrm{MHCll}, \mathrm{MHCl}$ and/or $\mathrm{MHCl}$-like ligands? Are there situations where this early checkpoint is breached, so that large numbers of self-reactive thymocytes are misdirected into the peripheral lymphoid organs? Would such misdirection compromise $T$ cell tolerance and immunity?

Wave 2 is intertwined with the selection of thymic T-reg cells and likely occurs in the thymic medulla. Insights into factors controlling this cell fate decision should come from testing whether the "avidity hypothesis" or the "collaboration hypothesis" holds more explanatory power. The "collaboration hypothesis" predicts that T-reg cells are more self-reactive than previously thought. Invernizzi and Gershwin wrote, "Since the first association study was published during the 1960s, MHC alleles have been found to be associated with almost every known human autoimmune disease."(145) The robustness of $T$ cell tolerance may be proportional to the difference in self-reactivity between T-reg cells and conventional T cells, which is set up in the thymus by the unique array of selfantigen/MHC ligands in each individual, in a process that requires elimination of superfluous thymocytes. 


\section{Acknowledgements}

SRD has received financial support from the Biomedicine Discovery Institute, Monash University, and from the National Health and Medical Research Council (NHMRC) Project Grant 1107464. CT is supported by NHMRC Early Career Fellowship 1089072. AS is supported by an NHMRC Senior Principal Research Fellow (SPRF) Fellowship 1020363, NHMRC Program Grant 1113113 and Leukemia and Lymphoma Society (SCOR grant 7413 and 7001-13). DHDG is supported by NHMRC Project Grant 1078763 and RD Wright Fellowship 1090236. This work was made possible through Victorian State Government Operational Infrastructure Support and Australian Government NHMRC IRIISS. The authors declare no conflict of interest.

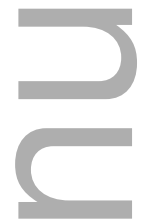

Figure 1. Overview of apoptotic checkpoints during $\mathrm{T}$ cell development in the thymus. The development of early thymic precursors (ETPs) into functional T cells can be defined by several stages based on the expression of CD4 and CD8 co-receptors CD4 $4^{-} \mathrm{CD} 8^{-}$double negative (DN), $\mathrm{CD} 4^{+} \mathrm{CD} 8^{+}$double positive (DP) and $\mathrm{CD} 4^{+} \mathrm{CD} 8^{-}$or $\mathrm{CD}^{-}{ }^{-} \mathrm{CD} 8^{+}$single positive (SP) stages. A pre-requisite of $\mathrm{T}$ cell development is the recombination of a functional $\mathrm{T}$ cell antigen receptor (TCR) that determines the ability of the $T$ cells to recognise $M H C$ ligands. Some $T C R \alpha \beta$ receptors that are non-functional or bind to a self-MHC ligand strongly are removed from the repertoire by apoptosis. The fate of the developing T cells hinges on the avidity (= strength) of the TCR $\alpha \beta /$ self-MHC ligand interaction, which may vary due to different arrays of self-MHC ligand expression in the cortex versus medulla. Cortical thymocytes that receive a strong $T C R \alpha \beta$ signal fail to activate nuclear factor kappa $\mathrm{B}(\mathrm{NF} \kappa \mathrm{B})$ and undergo deletion (Wave 1), although some cells survive and ultimately differentiate into small intestinal intra-epithelial lymphocytes (IEL). Weak TCR $\alpha \beta$ signalling in the cortex and medulla gives rise to $T_{\text {conv }}$ cells; however, strong TCR $\alpha \beta$ binding to a self-MHC ligand that is sequestered in the medulla upregulates expression of pro-apoptotic proteins BIM/PUMA, predisposing the cell to udnergo apoptosis. A minority of BIM/PUMA-high cells survive due to 
CARD11/NFKB signalling, to become pre- $\mathrm{T}_{\text {reg }}$ cells. We speculate that pre- $\mathrm{T}_{\text {reg }}$ cells "collaborate" with a small number of local dendritic cells (DC) and medullary thymic epithelial cells for a period of 1-2 days. Some pre- $T_{\text {reg }}$ cells are successful at inducing the $D C$ to synthesise IL-2, which the pre- $T_{\text {reg }}$ cell requires surviva and differentiate into a mature $\mathrm{FOXP} 3+\mathrm{T}_{\text {reg }}$ cell.

-

\section{REFERENCES:}

1. Petrie HT, Zuniga-Pflucker JC. Zoned out: functional mapping of stromal signaling microenvironments in the thymus. Annu Rev Immunol. 2007;25:649-679.

2. Raviola E, Karnovsky MJ. Evidence for a blood-thymus barrier using electronopaque tracers. J Exp Med. 1972;136:466-498.

3. Ladi E, Schwickert TA, Chtanova T, et al. Thymocyte-dendritic cell interactions near sources of CCR7 ligands in the thymic cortex. J Immunol. 2008;181:7014-7023. 4. McCaughtry TM, Wilken MS, Hogquist KA. Thymic emigration revisited. J Exp Med. 2007;204:2513-2520.

5. Foss DL, Donskoy E, Goldschneider I. The importation of hematogenous precursors by the thymus is a gated phenomenon in normal adult mice. $J$ Exp Med. 2001;193:365-374.

6. Koch U, Fiorini E, Benedito R, et al. Delta-like 4 is the essential, nonredundant ligand for Notch1 during thymic T cell lineage commitment. J Exp Med. 2008;205:25152523.

7. Hozumi K, Mailhos C, Negishi N, et al. Delta-like 4 is indispensable in thymic environment specific for T cell development. J Exp Med. 2008;205:2507-2513.

8. Zietara N, Lyszkiewicz M, Puchalka J, et al. Multicongenic fate mapping quantification of dynamics of thymus colonization. J Exp Med. 2015;212:1589-1601. 9. Godfrey DI, Kennedy J, Suda T, Zlotnik A. A developmental pathway involving four phenotypically and functionally distinct subsets of CD3-CD4-CD8- triple-negative adult mouse thymocytes defined by CD44 and CD25 expression. J Immunol. 1993;150:4244-4252. 
10. Yui MA, Rothenberg EV. Developmental gene networks: a triathlon on the course to T cell identity. Nat Rev Immunol. 2014;14:529-545.

11. Hayday AC, Pennington DJ. Key factors in the organized chaos of early $T$ cell development. Nat Immunol. 2007;8:137-144.

12. von Boehmer $\mathrm{H}$. Unique features of the pre-T-cell receptor $\alpha$-chain: not just a surrogate. NatRev Immunol. 2005;5:571-577.

13. Penit $C$, Lucas $B$, Vasseur $F$. Cell expansion and growth arrest phases during the transition from precursor (CD4-8-) to immature (CD4+8+) thymocytes in normal and genetically modified mice. J Immunol. 1995;154:5103-5113.

14. Penit C. Localization and phenotype of cycling and post-cycling murine thymocytes studied by simultaneous detection of bromodeoxyuridine and surface antigens. J Histochem Cytochem. 1988;36:473-478.

15. Kreslavsky $T$, Gleimer M, Miyazaki M, et al. $\beta$-Selection-induced proliferation is required for $\alpha \beta$ T cell differentiation. Immunity. 2012;37:840-853.

16. Guidos CJ, Danska JS, Fathman CG, Weissman IL. T cell receptor-mediated negative selection of autoreactive $T$ lymphocyte precursors occurs after commitment to the CD4 or CD8 lineages. J Exp Med. 1990;172:835-845.

17. Petrie HT, Livak F, Burtrum D, Mazel S. T cell receptor gene recombination patterns and mechanisms: cell death, rescue, and T cell production. J Exp Med. 1995;182:121-127.

18. Mingueneau M, Kreslavsky $T$, Gray D, et al. The transcriptional landscape of $\alpha \beta T$ cell differentiation. Nat Immunol. 2013;14:619-632.

19. Singer A, Adoro S, Park JH. Lineage fate and intense debate: myths, models and mechanisms of CD4- versus CD8-lineage choice. Nat Rev Immunol. 2008;8:788-801.

20. Miller JF. Immunological function of the thymus. Lancet. 1961;2:748-749.

21. Burnet M. Auto-immune disease. I. Modern immunological concepts. Br Med J. 1959;2:645-650.

22. Burnet M. Role of the thymus and related organs in immunity. Br Med J. 1962;2:807-811.

23. Nossal GJ. Negative selection of lymphocytes. Cell. 1994;76:229-239. 
24. Stritesky GL, Jameson SC, Hogquist KA. Selection of self-reactive T cells in the thymus. Annu Rev Immunol. 2012;30:95-114.

25. Strasser A, Cory S, Adams JM. Deciphering the rules of programmed cell death to improve therapy of cancer and other diseases. EMBO J. 2011;30:3667-3683.

26. Strasser A, O'Connor L, Dixit VM. Apoptosis signaling. Annu Rev Biochem. 2000;69:217-245.

27. Strasser A, Jost PJ, Nagata S. The many roles of FAS receptor signaling in the immune system. Immunity. 2009;30:180-192.

28. Weinlich R, Oberst A, Beere HM, Green DR. Necroptosis in development, inflammation and disease. Nat Rev Mol Cell Biol. 2016.

29. Alvarez-Diaz S, Dillon CP, Lalaoui N, et al. The Pseudokinase MLKL and the Kinase RIPK3 Have Distinct Roles in Autoimmune Disease Caused by Loss of DeathReceptor-Induced Apoptosis. Immunity. 2016;45:513-526.

30. Teh CE, Lalaoui $\mathrm{N}$, Jain $\mathrm{R}$, et al. Linear ubiquitin chain assembly complex coordinates late thymic T-cell differentiation and regulatory T-cell homeostasis. Nat Commun. 2016;7:13353.

31. Strasser A, Harris AW, Cory S. bcl-2 transgene inhibits T cell death and perturbs thymic self-censorship. Cell. 1991;67:889-899.

32. Bouillet $\mathrm{P}$, Purton JF, Godfrey $\mathrm{DI}$, et al. BH3-only Bcl-2 family member Bim is required for apoptosis of autoreactive thymocytes. Nature. 2002;415:922-926.

33. Bouillet $P$, Metcalf $D$, Huang DC, et al. Proapoptotic $\mathrm{Bcl}-2$ relative Bim required for certain apoptotic responses, leukocyte homeostasis, and to preclude autoimmunity. Science. 1999;286:1735-1738.

34. Rathmell JC, Lindsten T, Zong WX, Cinalli RM, Thompson CB. Deficiency in Bak and Bax perturbs thymic selection and lymphoid homeostasis. Nat Immunol. 2002;3:932-939.

35. Strasser A. The role of BH3-only proteins in the immune system. Nat Rev Immunol. 2005;5:189-200.

36. Czabotar PE, Lessene G, Strasser A, Adams JM. Control of apoptosis by the BCL-2 protein family: implications for physiology and therapy. Nat Rev Mol Cell Biol. 2014;15:49-63. 
37. Ke F, Voss A, Kerr JB, et al. BCL-2 family member BOK is widely expressed but its loss has only minimal impact in mice. Cell Death Differ. 2012;19:915-925.

38. Youle RJ, Strasser A. The BCL-2 protein family: opposing activities that mediate cell death. Nat Rev Mol Cell Biol. 2008;9:47-59.

39. Llambi F, Moldoveanu T, Tait SW, et al. A unified model of mammalian BCL-2 protein family interactions at the mitochondria. Mol Cell. 2011;44:517-531.

40. O'Neill KL, Huang K, Zhang J, Chen Y, Luo X. Inactivation of prosurvival Bcl-2 proteins activates Bax/Bak through the outer mitochondrial membrane. Genes Dev. 2016;30:973-988.

41. Acehan D, Jiang X, Morgan DG, Heuser JE, Wang X, Akey CW. Threedimensional structure of the apoptosome: implications for assembly, procaspase- 9 binding, and activation. Mol Cell. 2002;9:423-432.

42. Kluck RM, Bossy-Wetzel E, Green DR, Newmeyer DD. The release of cytochrome $\mathrm{c}$ from mitochondria: a primary site for $\mathrm{Bcl}-2$ regulation of apoptosis. Science. 1997;275:1132-1136.

43. Riedl SJ, Salvesen GS. The apoptosome: signalling platform of cell death. Nat Rev Mol Cell Biol. 2007;8:405-413.

44. Jost PJ, Grabow S, Gray D, et al. XIAP discriminates between type I and type II FAS-induced apoptosis. Nature. 2009;460:1035-1039.

45. Riedl SJ, Renatus M, Schwarzenbacher R, et al. Structural basis for the inhibition of caspase-3 by XIAP. Cell. 2001;104:791-800.

46. Verhagen AM, Ekert PG, Pakusch M, et al. Identification of DIABLO, a mammalian protein that promotes apoptosis by binding to and antagonizing IAP proteins. Cell. 2000;102:43-53.

47. Rongvaux A, Jackson R, Harman CC, et al. Apoptotic caspases prevent the induction of type I interferons by mitochondrial DNA. Cell. 2014;159:1563-1577.

48. White $M J$, McArthur $K$, Metcalf $D$, et al. Apoptotic caspases suppress mtDNAinduced STING-mediated type I IFN production. Cell. 2014;159:1549-1562.

49. Lindsten $\mathrm{T}$, Ross AJ, King A, et al. The combined functions of proapoptotic Bcl-2 family members bak and bax are essential for normal development of multiple tissues. Mol Cell. 2000;6:1389-1399. 
50. Mandal M, Borowski C, Palomero T, et al. The BCL2A1 gene as a pre-T cell receptor-induced regulator of thymocyte survival. J Exp Med. 2005;201:603-614. 51. Mandal M, Crusio KM, Meng F, et al. Regulation of lymphocyte progenitor survival by the proapoptotic activities of Bim and Bid. Proc Natl Acad Sci U S A. 2008;105:20840-20845.

52. Voll RE, Jimi E, Phillips RJ, et al. NF-kappa B activation by the pre-T cell receptor serves as a selective survival signal in T lymphocyte development. Immunity. 2000;13:677-689.

53. Pang SS, Berry R, Chen Z, et al. The structural basis for autonomous dimerization of the pre-T-cell antigen receptor. Nature. 2010;467:844-848.

54. Kaufmann T, Tai L, Ekert PG, et al. The BH3-only protein bid is dispensable for DNA damage- and replicative stress-induced apoptosis or cell-cycle arrest. Cell. 2007;129:423-433.

55. Herold MJ, Rohrbeck L, Lang MJ, et al. Foxo-mediated Bim transcription is dispensable for the apoptosis of hematopoietic cells that is mediated by this $\mathrm{BH}$-only protein. EMBO Rep. 2013;14:992-998.

56. Ottina E, Grespi F, Tischner D, et al. Targeting antiapoptotic A1/Bfl-1 by in vivo RNAi reveals multiple roles in leukocyte development in mice. Blood. 2012;119:60326042.

57. Strasser A, Harris AW, Corcoran LM, Cory S. Bcl-2 expression promotes B- but not T-lymphoid development in scid mice. Nature. 1994;368:457-460.

58. Araki R, Fujimori A, Hamatani K, et al. Nonsense mutation at Tyr-4046 in the DNA-dependent protein kinase catalytic subunit of severe combined immune deficiency mice. Proc Natl Acad Sci U S A. 1997;94:2438-2443.

59. Blunt $T$, Gell $D$, Fox $M$, et al. Identification of a nonsense mutation in the carboxylterminal region of DNA-dependent protein kinase catalytic subunit in the scid mouse. Proc Natl Acad Sci U S A. 1996;93:10285-10290.

60. Newton K, Harris AW, Strasser A. FADD/MORT1 regulates the pre-TCR checkpoint and can function as a tumour suppressor. EMBO J. 2000;19:931-941.

61. Egerton M, Scollay R, Shortman K. Kinetics of mature T-cell development in the thymus. Proc Natl Acad Sci U S A. 1990;87:2579-2582. 
62. Petrie HT, Livak F, Schatz DG, Strasser A, Crispe IN, Shortman K. Multiple rearrangements in T cell receptor $\alpha$ chain genes maximize the production of useful thymocytes. J Exp Med. 1993;178:615-622.

63. Strasser A, Harris AW, von Boehmer H, Cory S. Positive and negative selection of $\mathrm{T}$ cells in T-cell receptor transgenic mice expressing a bcl-2 transgene. Proc Natl Acad Sci U S A. 1994;91:1376-1380.

64. Ma A, Pena JC, Chang B, et al. Bclx regulates the survival of double-positive thymocytes. Proc Natl Acad Sci U S A. 1995;92:4763-4767.

65. Sun Z, Unutmaz D, Zou YR, et al. Requirement for ROR $\gamma$ in thymocyte survival and lymphoid organ development. Science. 2000;288:2369-2373.

66. Kurebayashi S, Ueda E, Sakaue M, et al. Retinoid-related orphan receptor $\gamma$ (ROR $\gamma$ ) is essential for lymphoid organogenesis and controls apoptosis during thymopoiesis. Proc Natl Acad Sci U S A. 2000;97:10132-10137.

67. Guo J, Hawwari A, $\mathrm{Li} \mathrm{H}$, et al. Regulation of the TCR $\alpha$ repertoire by the survival window of CD4+CD8+ thymocytes. Nat Immunol. 2002;3:469-476.

68. Mason KD, Carpinelli MR, Fletcher JI, et al. Programmed anuclear cell death delimits platelet life span. Cell. 2007;128:1173-1186.

69. Bouillet P, Cory S, Zhang LC, Strasser A, Adams JM. Degenerative disorders caused by Bcl-2 deficiency prevented by loss of its $\mathrm{BH} 3$-only antagonist Bim. Dev Cell. $2001 ; 1: 645-653$.

70. Veis DJ, Sorenson CM, Shutter JR, Korsmeyer SJ. Bcl-2-deficient mice demonstrate fulminant lymphoid apoptosis, polycystic kidneys, and hypopigmented hair. Cell. 1993;75:229-240.

71. Dzhagalov I, Dunkle A, He YW. The anti-apoptotic Bcl-2 family member Mcl-1 promotes T lymphocyte survival at multiple stages. J Immunol. 2008;181:521-528.

72. Gray DH, Kupresanin F, Berzins SP, et al. The BH3-only proteins Bim and Puma cooperate to impose deletional tolerance of organ-specific antigens. Immunity. 2012;37:451-462.

73. Billingham RE, Brent L, Medawar PB. Actively acquired tolerance of foreign cells. Nature. 1953;172:603-606. 
74. Sprent J, Lo D, Gao EK, Ron Y. T cell selection in the thymus. Immunol Rev. 1988;101:173-190.

75. Kappler JW, Roehm N, Marrack P. T cell tolerance by clonal elimination in the thymus. Cell. 1987;49:273-280.

76. Wang $L$, Zhao Y, Li Z, et al. Crystal structure of a complete ternary complex of TCR, superantigen and peptide-MHC. Nat Struct Mol Biol. 2007;14:169-171.

77. Kisielow $P$, Bluthmann $H$, Staerz UD, Steinmetz $M$, von Boehmer H. Tolerance in T-cell-receptor transgenic mice involves deletion of nonmature CD4+8+ thymocytes. Nature. 1988;333:742-746.

78. Pircher $\mathrm{H}$, Burki K, Lang R, Hengartner $\mathrm{H}$, Zinkernagel RM. Tolerance induction in double specific T-cell receptor transgenic mice varies with antigen. Nature. 1989;342:559-561.

79. Baldwin KK, Trenchak BP, Altman JD, Davis3 MM. Negative Selection of T Cells Occurs Throughout Thymic Development. The Journal of Immunology. 1999;163:689698.

80. Malhotra D, Linehan JL, Dileepan T, et al. Tolerance is established in polyclonal CD4+ T cells by distinct mechanisms, according to self-peptide expression patterns. Nat Immunol.2016;17:187-195.

81. Surh CD, Sprent J. T-cell apoptosis detected in situ during positive and negative selection in the thymus. Nature. 1994;372:100-103.

82. Douek DC, Corley KTT, Zal T, Mellor A, Dyson PJ, Altmann DM. Negative selection by endogenous antigen and superantigen occurs at multiple thymic sites. International Immunology. 1996;8:1413-1420.

83. McCaughtry TM, Baldwin TA, Wilken MS, Hogquist KA. Clonal deletion of thymocytes can occur in the cortex with no involvement of the medulla. $J$ Exp Med. 2008;205:2575-2584.

84. Stritesky GL, Xing Y, Erickson JR, et al. Murine thymic selection quantified using a unique method to capture deleted T cells. Proc Natl Acad Sci U S A. 2013;110:46794684. 
85. Hu DY, Yap JY, Wirasinha RC, Howard DR, Goodnow CC, Daley SR. A timeline demarcating two waves of clonal deletion and Foxp3 upregulation during thymocyte development. Immunol Cell Biol. 2016;94:357-366.

86. Ehrlich LI, Oh DY, Weissman IL, Lewis RS. Differential contribution of chemotaxis and substrate restriction to segregation of immature and mature thymocytes. Immunity. 2009;31:986-998.

87. Halkias J, Melichar HJ, Taylor KT, et al. Opposing chemokine gradients control human thymocyte migration in situ. The Journal of Clinical Investigation. 2013;123:21312142.

88. Melichar HJ, Ross JO, Herzmark P, Hogquist KA, Robey EA. Distinct temporal pattern of T cell receptor signals during positive versus negative selection in situ. Science signaling. 2013;6:ra92-ra92.

89. Dzhagalov IL, Chen KG, Herzmark P, Robey EA. Elimination of Self-Reactive T Cells in the Thymus: A Timeline for Negative Selection. PLoS Biol. 2013;11:e1001566. 90. Le Borgne M, Ladi E, Dzhagalov I, et al. The impact of negative selection on thymocyte migration in the medulla. Nat Immunol. 2009;10:823-830.

91. Ueda Y, Katagiri K, Tomiyama T, et al. Mst1 regulates integrin-dependent thymocyte trafficking and antigen recognition in the thymus. Nat Commun. 2012;3:1098. 92. Moran AE, Holzapfel KL, Xing $\mathrm{Y}$, et al. T cell receptor signal strength in Treg and iNKT cell development demonstrated by a novel fluorescent reporter mouse. J Exp Med. 2011;208:1279-1289.

93. Daley SR, Hu DY, Goodnow CC. Helios marks strongly autoreactive CD4+ T cells in two major waves of thymic deletion distinguished by induction of PD-1 or NF-kappaB. J Exp Med. 2013;210:269-285.

94. Sinclair C, Bains I, Yates AJ, Seddon B. Asymmetric thymocyte death underlies the CD4:CD8 T-cell ratio in the adaptive immune system. Proc Natl Acad Sci U S A. 2013;110:E2905-2914.

95. Yu W, Jiang N, Ebert PJ, et al. Clonal Deletion Prunes but Does Not Eliminate Self-Specific $\alpha \beta$ CD8+ T Lymphocytes. Immunity. 2015;42:929-941. 
96. Chu HH, Moon JJ, Kruse AC, Pepper M, Jenkins MK. Negative selection and peptide chemistry determine the size of naive foreign peptide-MHC class II-specific CD4+ T cell populations. J Immunol. 2010;185:4705-4713.

97. McDonald BD, Bunker JJ, Erickson SA, Oh-Hora M, Bendelac A. Crossreactive $\alpha \beta$ T Cell Receptors Are the Predominant Targets of Thymocyte Negative Selection. Immunity. 2015;43:859-869.

98. Newton K, Harris AW, Bath ML, Smith KG, Strasser A. A dominant interfering mutant of $F A D D / M O R T 1$ enhances deletion of autoreactive thymocytes and inhibits proliferation of mature T lymphocytes. EMBO J. 1998;17:706-718.

99. Hu Q, Sader A, Parkman JC, Baldwin TA. Bim-mediated apoptosis is not necessary for thymic negative selection to ubiquitous self-antigens. J Immunol. 2009;183:7761-7767.

100. Davey GM, Kurts C, Miller JF, et al. Peripheral deletion of autoreactive CD8 T cells by cross presentation of self-antigen occurs by a Bcl-2-inhibitable pathway mediated by Bim. J Exp Med. 2002;196:947-955.

101. McDonald BD, Bunker JJ, Ishizuka IE, Jabri B, Bendelac A. Elevated T cell receptor signaling identifies a thymic precursor to the TCR $\alpha \beta+C D 4-C D 8 \beta$ - intraepithelial lymphocyte lineage. Immunity. 2014;41:219-229.

102. Suen AY, Baldwin TA. Proapoptotic protein Bim is differentially required during thymic clonal deletion to ubiquitous versus tissue-restricted antigens. Proc Natl Acad Sci U S A. 2012;109:893-898.

103. Zhan Y, Zhang Y, Gray D, et al. Defects in the Bcl-2-regulated apoptotic pathway lead to preferential increase of CD25 low Foxp3+ anergic CD4+ T cells. J Immunol. 2011;187:1566-1577.

104. Tai X, Erman B, Alag A, et al. Foxp3 transcription factor is proapoptotic and lethal to developing regulatory $T$ cells unless counterbalanced by cytokine survival signals. Immunity . 2013;38:1116-1128.

105. Liston A, Lesage S, Gray DH, et al. Generalized resistance to thymic deletion in the NOD mouse; a polygenic trait characterized by defective induction of Bim. Immunity. 2004;21:817-830. 
106. Baldwin TA, Hogquist KA. Transcriptional analysis of clonal deletion in vivo. $J$ Immunol. 2007;179:837-844.

107. Calnan BJ, Szychowski S, Chan FK, Cado D, Winoto A. A role for the orphan steroid receptor Nur77 in apoptosis accompanying antigen-induced negative selection. Immunity. 1995;3:273-282.

108. Hu QN, Baldwin TA. Differential roles for Bim and Nur77 in thymocyte clonal deletion induced by ubiquitous self-antigen. J Immunol. 2015;194:2643-2653.

109. Fassett MS, Jiang W, D'Alise AM, Mathis D, Benoist C. Nuclear receptor Nr4a1 modulates both regulatory T-cell (Treg) differentiation and clonal deletion. Proc Natl Acad Sci U S A. 2012;109:3891-3896.

110. Woronicz JD, Calnan B, Ngo V, Winoto A. Requirement for the orphan steroid receptor Nur77 in apoptosis of T-cell hybridomas. Nature. 1994;367:277-281.

111. Leishman AJ, Gapin L, Capone M, et al. Precursors of functional MHC class I- or class II-restricted CD $8 \alpha \alpha+T$ cells are positively selected in the thymus by agonist selfpeptides. Immunity. 2002;16:355-364.

112. Mayans S, Stepniak D, Palida SF, et al. $\alpha \beta$ T cell receptors expressed by CD4$\mathrm{CD} 8 \alpha \beta$ - intraepithelial T cells drive their fate into a unique lineage with unusual $\mathrm{MHC}$ reactivities. Immunity. 2014;41:207-218.

113. Swat $\mathrm{W}$, Ignatowicz $\mathrm{L}$, von Boehmer $\mathrm{H}$, Kisielow $\mathrm{P}$. Clonal deletion of immature CD4+8+ thymocytes in suspension culture by extrathymic antigen-presenting cells. Nature. 1991;351:150-153.

114. Gangadharan D, Lambolez F, Attinger A, Wang-Zhu Y, Sullivan BA, Cheroutre H. Identification of pre- and postselection TCR $\alpha \beta+$ intraepithelial lymphocyte precursors in the thymus. Immunity. 2006;25:631-641.

115. Hanke $T$, Mitnacht R, Boyd R, Hunig $T$. Induction of interleukin 2 receptor $\beta$ chain expression by self-recognition in the thymus. $J$ Exp Med. 1994;180:1629-1636.

116. Pobezinsky LA, Angelov GS, Tai X, et al. Clonal deletion and the fate of autoreactive thymocytes that survive negative selection. Nat Immunol. 2012;13:569-578. 117. Das G, Janeway CA, Jr. Development of CD8 $\alpha / \alpha$ and CD $8 \alpha / \beta$ T cells in major histocompatibility complex class I-deficient mice. J Exp Med. 1999;190:881-884. 
118. Leishman AJ, Naidenko OV, Attinger A, et al. T cell responses modulated through interaction between CD8 $\alpha \alpha$ and the nonclassical MHC class I molecule, TL. Science. 2001;294:1936-1939.

119. Hershberg R, Eghtesady $\mathrm{P}$, Sydora B, et al. Expression of the thymus leukemia antigen in mouse intestinal epithelium. Proc Natl Acad Sci U S A. 1990;87:9727-9731. 120. Gavin MA, Rasmussen JP, Fontenot JD, et al. Foxp3-dependent programme of regulatory T-cell differentiation. Nature. 2007;445:771-775.

121. Hori S, Nomura T, Sakaguchi S. Control of regulatory T cell development by the transcription factor Foxp3. Science. 2003;299:1057-1061.

122. Kim JM, Rasmussen JP, Rudensky AY. Regulatory T cells prevent catastrophic autoimmunity throughout the lifespan of mice. Nat Immunol. 2007;8:191-197.

123. Wildin RS, Ramsdell F, Peake J, et al. X-linked neonatal diabetes mellitus, enteropathy and endocrinopathy syndrome is the human equivalent of mouse scurfy. Nat Genet. 2001;27:18-20.

124. Bennett CL, Christie J, Ramsdell F, et al. The immune dysregulation, polyendocrinopathy, enteropathy, X-linked syndrome (IPEX) is caused by mutations of FOXP3. Nat Genet. 2001;27:20-21.

125. Li MO, Rudensky AY. T cell receptor signalling in the control of regulatory $\mathrm{T}$ cell differentiation and function. Nat Rev Immunol. 2016;16:220-233.

126. Ohkura N, Hamaguchi M, Morikawa $\mathrm{H}$, et al. T cell receptor stimulation-induced epigenetic changes and Foxp3 expression are independent and complementary events required for Treg cell development. Immunity. 2012;37:785-799.

127. Cowan JE, Parnell SM, Nakamura K, et al. The thymic medulla is required for Foxp3+ regulatory but not conventional CD4+ thymocyte development. J Exp Med. 2013;210:675-681.

128. Klein L, Kyewski B, Allen PM, Hogquist KA. Positive and negative selection of the T cell repertoire: what thymocytes see (and don't see). Nat Rev Immunol. 2014;14:377391.

129. Tai X, Cowan M, Feigenbaum L, Singer A. CD28 costimulation of developing thymocytes induces Foxp3 expression and regulatory $T$ cell differentiation independently of interleukin 2. Nat Immunol. 2005;6:152-162. 
130. Vang KB, Yang J, Pagan AJ, et al. Cutting edge: CD28 and c-Rel-dependent pathways initiate regulatory T cell development. J Immunol. 2010;184:4074-4077.

131. Hinterberger M, Wirnsberger G, Klein L. B7/CD28 in central tolerance:

costimulation promotes maturation of regulatory $T$ cell precursors and prevents their clonal deletion. Front Immunol. 2011;2:30.

132. Lio CW, Hsieh CS. A two-step process for thymic regulatory $T$ cell development. Immunity. 2008;28:100-111.

133. Fontenot JD, Rasmussen JP, Gavin MA, Rudensky AY. A function for interleukin 2 in Foxp3-expressing regulatory T cells. Nat Immunol. 2005;6:1142-1151.

134. Burchill MA, Yang J, Vang KB, et al. Linked T cell receptor and cytokine signaling govern the development of the regulatory T cell repertoire. Immunity. 2008;28:112-121. 135. Hinterberger M, Aichinger M, da Costa OP, Voehringer D, Hoffmann R, Klein L. Autonomous role of medullary thymic epithelial cells in central CD4+ T cell tolerance. Nat Immunol. 2010;11:512-519.

136. Marshall D, Sinclair C, Tung S, Seddon B. Differential requirement for IL-2 and IL15 during bifurcated development of thymic regulatory T cells. J Immunol. 2014;193:5525-5533.

137. Bautista JL, Lio CW, Lathrop SK, et al. Intraclonal competition limits the fate determination of regulatory T cells in the thymus. Nat Immunol. 2009;10:610-617. 138. Leung MW, Shen S, Lafaille JJ. TCR-dependent differentiation of thymic Foxp3+ cells is limited to small clonal sizes. J Exp Med. 2009;206:2121-2130.

139. Cozzo Picca C, Simons DM, Oh S, et al. CD4+CD25+Foxp3+ regulatory T cell formation requires more specific recognition of a self-peptide than thymocyte deletion. Proc Natl Acad Sci U S A. 2011;108:14890-14895.

140. Weist BM, Kurd N, Boussier J, Chan SW, Robey EA. Thymic regulatory T cell niche size is dictated by limiting IL-2 from antigen-bearing dendritic cells and feedback competition. Nat Immunol. 2015;16:635-641.

141. Lee HM, Bautista JL, Scott-Browne J, Mohan JF, Hsieh CS. A broad range of self-reactivity drives thymic regulatory $\mathrm{T}$ cell selection to limit responses to self. Immunity. 2012;37:475-486.

This article is protected by copyright. All rights reserved 
142. Kieback E, Hilgenberg E, Stervbo U, et al. Thymus-Derived Regulatory T Cells Are Positively Selected on Natural Self-Antigen through Cognate Interactions of High Functional Avidity. Immunity. 2016;44:1114-1126.

143. Yang-Snyder JA, Rothenberg EV. Spontaneous expression of interleukin-2 in vivo in specific tissues of young mice. Dev Immunol. 1998;5:223-245.

144. Wyss L, Stadinski BD, King CG, et al. Affinity for self antigen selects Treg cells with distinct functional properties. Nat Immunol. 2016;17:1093-1101.

145. Invernizzi P, Gershwin ME. The genetics of human autoimmune disease. $J$ Autoimmun. 2009;33:290-299.

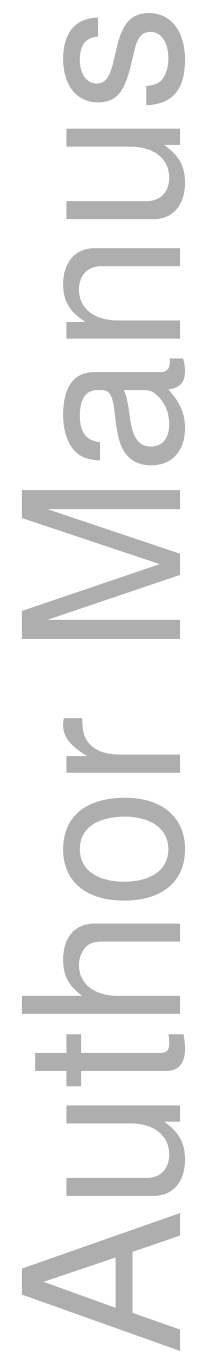

This article is protected by copyright. All rights reserved 
Figure 1

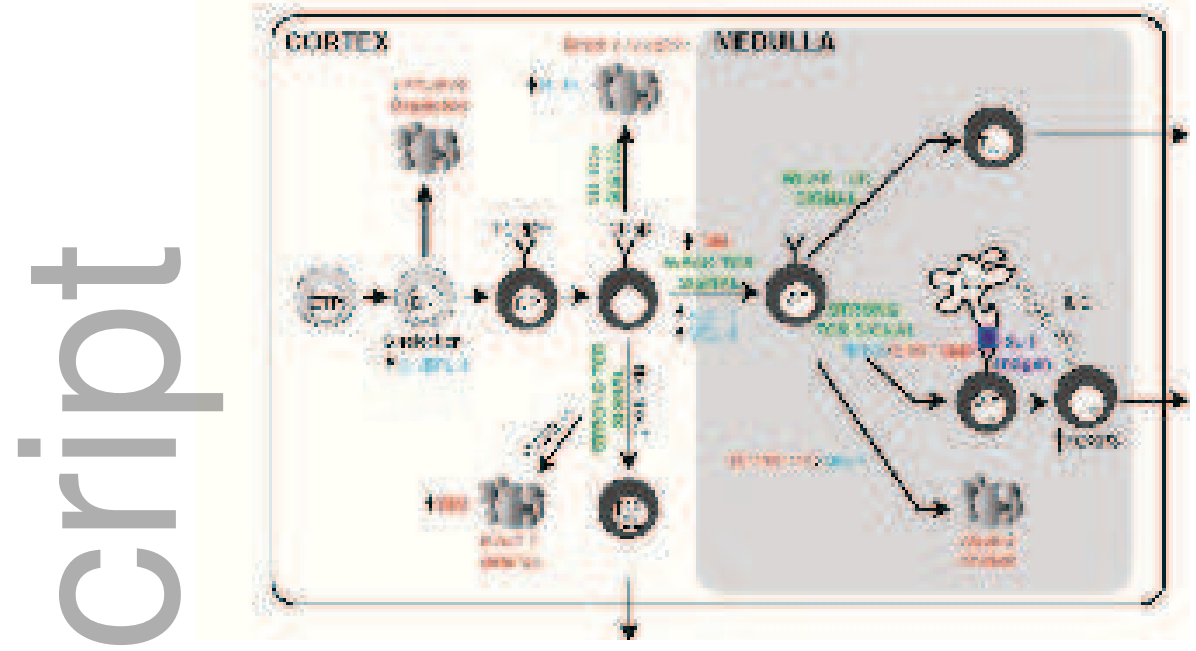

imr_12532_f1.tiff

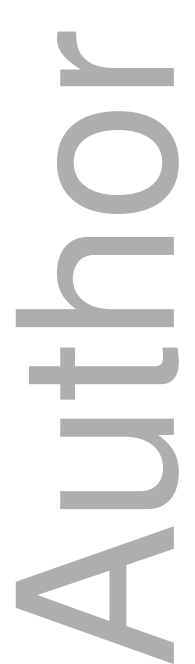




\section{University Library}

\section{- M M I N E R VA A gateway to Melbourne's research publications}

Minerva Access is the Institutional Repository of The University of Melbourne

Author/s:

Daley, SR;Teh, C;Hu, DY;Strasser, A;Gray, DHD

Title:

Cell death and thymic tolerance

Date:

2017-05-01

Citation:

Daley, S. R., Teh, C., Hu, D. Y., Strasser, A. \& Gray, D. H. D. (2017). Cell death and thymic

tolerance. IMMUNOLOGICAL REVIEWS, 277 (1), pp.9-20. https://doi.org/10.1111/imr.12532.

Persistent Link:

http://hdl.handle.net/11343/292826 